\title{
Advanced medullary thyroid cancer: pathophysiology and management
}

\author{
This article was published in the following Dove Press journal: \\ Cancer Management and Research \\ 7 May 2013 \\ Number of times this article has been viewed
}

\section{Carla Vaz Ferreira \\ Débora Rodrigues Siqueira \\ Lucieli Ceolin \\ Ana Luiza Maia}

Thyroid Section, Endocrine Division, Hospital de Clínicas de Porto Alegre, Porto Alegre, Brazil
Correspondence: Ana Luiza Maia Thyroid Section, Endocrine Division, Hospital de Clínicas de Porto Alegre, 2350 Rua Ramiro Barcelos, Porto Alegre, RS 90035 003, Brazil

Tel 555 I 33598127

Fax 55 5। 333। 0207

Email almaia@ufrgs.br

\begin{abstract}
Medullary thyroid carcinoma (MTC) is a rare malignant tumor originating from thyroid parafollicular C cells. This tumor accounts for 3\%-4\% of thyroid gland neoplasias. MTC may occur sporadically or be inherited. Hereditary MTC appears as part of the multiple endocrine neoplasia syndrome type $2 \mathrm{~A}$ or $2 \mathrm{~B}$, or familial medullary thyroid cancer. Germ-line mutations of the RET proto-oncogene cause hereditary forms of cancer, whereas somatic mutations can be present in sporadic forms of the disease. The RET gene encodes a receptor tyrosine kinase involved in the activation of intracellular signaling pathways leading to proliferation, growth, differentiation, migration, and survival. Nowadays, early diagnosis of MTC followed by total thyroidectomy offers the only possibility of cure. Based on the knowledge of the pathogenic mechanisms of MTC, new drugs have been developed in an attempt to control metastatic disease. Of these, small-molecule tyrosine kinase inhibitors represent one of the most promising agents for MTC treatment, and clinical trials have shown encouraging results. Hopefully, the cumulative knowledge about the targets of action of these drugs and about the tyrosine kinase inhibitor-associated side effects will help in choosing the best therapeutic approach to enhance their benefits.
\end{abstract}

Keywords: medullary thyroid carcinoma, proto-oncogene $R E T$, tyrosine kinase inhibitors

\section{Introduction}

Medullary thyroid carcinoma (MTC) is a rare malignant tumor originating from parafollicular C cells of the thyroid, first described by Hazard et al. ${ }^{1}$ This tumor accounts for $3 \%-4 \%$ of all thyroid gland neoplasias. ${ }^{2}$ Calcitonin, the main secretory product of MTC, is a specific and highly sensitive biomarker for $\mathrm{C}$-cell disease. The carcinoembryonic antigen (CEA) is also produced by neoplastic $\mathrm{C}$ cells. These molecules are widely used as prognostic markers during the follow-up of MTC patients. ${ }^{3,4}$ The reported 10-year mortality rate for patients with MTC varies from $13.5 \%$ to $38 \%{ }^{5,6}$

MTC may occur sporadically (75\% of cases), or as part of the inherited cancer syndrome known as multiple endocrine neoplasia (MEN) type 2.7.8 The term MEN was introduced by Steiner et al in 1968 to describe disorders that include a combination of endocrine tumors. The Wermer syndrome was designed as MEN 1, and the Sipple syndrome as MEN 2. ${ }^{9}$ Later, MEN 2 was subdivided into three distinct syndromes: MEN 2A, MEN 2B, and familial medullary thyroid carcinoma (FMTC). Hereditary MTC is usually preceded by $\mathrm{C}$-cell hyperplasia, and these tumors are generally bilateral and multicentric. The mean age at diagnosis is around 45 years. ${ }^{6,10}$

The MEN 2A subtype constitutes approximately 70\%-80\% of cases of MEN 2 and is characterized by the presence of MTC (95\%), pheochromocytoma (30\%-50\%) and hyperparathyroidism $(10 \%-20 \%)$. Adrenomedullary disease is usually multicentric and 
bilateral (65\%-78\%), generally detected after the onset of MTC. ${ }^{11,12}$ Two rare variants of MEN 2A have been described: one with cutaneous lichen amyloidosis, a pruriginous lesion of the scapular region characterized by amyloid deposition, and the other with Hirschsprung's disease, caused by the absence of autonomic ganglia in the terminal hindgut that results in colonic dilatation, obstipation, and constipation. ${ }^{13,14}$ The clinical course of MTC in patients with MEN 2A is variable, and the disease progression is associated with codonspecific mutations. ${ }^{11,15}$

The MEN 2B syndrome accounts for about $5 \%$ of the cases of MEN 2. MEN 2B is characterized by a single phenotype, which includes diffuse ganglioneuromatosis of the tongue, lips, eyes, and gastrointestinal tract, and Marfanoid habitus. MEN 2B patients present with MTC (>90\%), pheochromocytoma (45\%), ganglioneuromatosis (100\%), and Marfanoid habitus (65\%). ${ }^{11,12}$ MTC in the setting of MEN 2B develops earlier and has a more aggressive course, compared with MTC in other MEN 2 subtypes. ${ }^{6,16}$

The FMTC subtype constitutes $10 \%-20 \%$ of the cases of MEN 2. ${ }^{11}$ MTC is the only manifestation of FMTC, thereby it is necessary to demonstrate the absence of a pheochromocytoma or hyperparathyroidism in two or more generations of the same family or the identification of related mutations to confirm the diagnosis. The clinical presentation of MTC occurs later, and the prognosis is more favorable compared to the other forms of MTC. ${ }^{17}$

Sporadic MTC generally presents as a palpable thyroid nodule or cervical lymph node. Diagnosis tends to be late, generally in the fifth or sixth decade of life. ${ }^{18}$ Lymph-node metastases are detected in at least $50 \%$ of these patients at diagnosis, while distant metastases occur in around $20 \%$ of cases. ${ }^{19,20}$ A minority of patients with MTC present systemic manifestations that include diarrhea, flushing, or painful bone metastases. ${ }^{16}$

\section{Epidemiology, etiology, and pathophysiology of familial and sporadic medullary thyroid cancer}

MTC represents approximately $3 \%-4 \%$ of malignant thyroid gland neoplasias. ${ }^{2}$ The Surveillance, Epidemiology, and End Results (SEER) program of the National Cancer Institute showed that MTC patients had a median age of 50 years at diagnosis and were white in the majority of the cases. There is no difference in the frequency of this tumor between sexes..$^{21,22}$
Hereditary MTC affects approximately one in 30,000 individuals and is associated with germ-line mutations in the RET (Re arranged during Transfection) proto-oncogene, an autosomal dominant disease with a high penetrance and variable phenotype. RET point mutations affect mainly exons 10,11 , and 16. Less common mutations occur in exons 5 , $8,13,14$, and $15 . .^{21,23}$

The RET gene encodes a receptor tyrosine kinase (RTK), expressed in cells derived from the neural crest: thyroid parafollicular cells ( $\mathrm{C}$ cells), parathyroid cells, and chromaffin cells of the adrenal medulla and enteric autonomic plexus. The RET protein is constituted by three domains: extracellular, transmembrane, and intracellular. The extracellular domain includes regions homologous to the cadherin family of cell-adhesion molecules and a large region rich in cysteine residues that performs the transduction of extracellular signals of cell proliferation, differentiation, migration, survival, and apoptosis. The intracellular domain encloses two tyrosine kinase subdomains - TK1 and TK2 - which contain the tyrosine residues involved in the activation of the signaling intracellular pathways. The RET gene is subject to alternative splicing of the $3^{\prime}$ region, generating three distinct protein isoforms, with 9 (RET9), 43 (RET43) and 51 (RET51) amino acids in the carboxy-terminal tail downstream from glycine 1063. RET9 and RET51, consisting of 1072 and 1114 amino acids, respectively, are the main isoforms. ${ }^{24,25}$

The majority of families with MEN 2A (>90\%) present point mutations in the RET proto-oncogene (missense type), involving codons located in the extracellular region: 609, 611, 618, and 620 (exon 10) and 634 (exon 11). The most frequent mutations are located in codon 634, occurring in more than $60 \%$ of all genetically identified MTC. ${ }^{11,17,21,26}$ Codon 634 mutations have been associated with the presence of pheochromocytoma and hyperparathyroidism, ${ }^{27}$ and rarely with cutaneous lichen amyloidosis. ${ }^{28}$ Nevertheless, we observe a variety of phenotypic expressions in families with the same $R E T$ mutation. ${ }^{11,29-32}$ Patients harboring the genotype C634R (TGC/Cys $\rightarrow$ CGC/Arg, exon 11) present significantly more distant metastases at diagnosis than groups C634W (Cys/TGC $\rightarrow$ Trp/TGG, exon 11) and C634Y (Cys/TGC $\rightarrow$ Tyr/TAC, exon 11), suggesting that a change of specific amino acids may modify the natural development of the disease. ${ }^{32}$ The RET C634W mutation is associated with high penetrance for MTC and pheochromocytoma. ${ }^{26}$ The risk profiles and penetrance estimations in MEN 2A caused by germ-line RET exon 10 mutations were recently analyzed by Frank-Raue et al in a large multicenter study that 
included 340 subjects from 103 families. It was observed that mutations affect mainly the cysteine codons $609,611,618$, and 620 , and $50 \%$ penetrance was achieved by the age of 36 years for MTC, by 68 years for pheochromocytoma, and by 82 years for hyperparathyroidism. ${ }^{30}$

MEN 2B occurs, in approximately $95 \%$ of the cases, through a specific M918T mutation (exon 16), resulting in structural change of the intracellular domain of the RET protein. The genotype A883F (GCT $\rightarrow$ TTT, exon 15) accounts for about $2 \%-3 \%$ of cases, and 33,34 a doublemutation V804M/Y806C at codon 804 (Val/GTG $\rightarrow$ Met/ATG, exon 14) and 806 (Tyr/TAC $\rightarrow$ Cys/TGC) in the same allele was described in a patient with MEN 2B. Patients presenting with "atypical" MEN 2B harboring the germ-line double-point mutation in codons 804 and 904 (V804M and S904C) were also reported. ${ }^{35,36}$ Mutations in codons 883 and 918 are associated with younger age of MTC onset and higher risk of metastases and diseasespecific mortality. ${ }^{10,11,37}$

In FMTC, germ-line mutations are distributed throughout the RET gene; approximately $86 \%-88 \%$ of FMTC families present mutations in exon 10 (codons 609, 611, 618, 620) and exon 11 (codon 634) of RET. ${ }^{31,38}$ Substitutions in the intracellular domain of RET in exon 13 (codon 768, 790, 791), exon 14 (codon 804 and 844), and exon 15 (codon 891) are less common. Interestingly, the most frequent mutation observed in MEN 2A, C634R, has not been described in FMTC families. ${ }^{11,38-41}$

On the other hand, the molecular mechanisms involved in sporadic MTC have not yet been clarified. About $50 \%-80 \%$ of cases present the somatic RET mutation M918T $\left(\mathrm{Met} / \mathrm{ATG} \rightarrow \mathrm{Thr} / \mathrm{ACG}\right.$, exon 16). ${ }^{42,43}$ Somatic mutations in codons $618,603,634,768,804$, and 883 and partial deletion of the RET gene have been identified in a few tumors. ${ }^{19,20}$ However, the mutation does not appear to be uniform among the various cell subpopulations in the tumor or in the metastases, suggesting that sporadic MTC might be of polyclonal origin, or that the mutations in the RET proto-oncogene are not initial events in MTC tumorigenesis. ${ }^{42,44}$

The presence of a somatic RET (M918T) mutation correlates with higher probability of persistent disease and lower survival rate in a long-term follow up..$^{19,20}$

In recent years, the presence of $R E T$ variant sequences or polymorphisms have been associated with susceptibility for the development or progression of MTC. Several studies have described increased prevalence of RET polymorphisms in individuals with hereditary or sporadic MTC when compared with the population. ${ }^{43,45-49}$

\section{Overview of current therapeutic strategies}

Surgery is the only curative treatment for MTC. ${ }^{10,16,50}$ There are no effective therapeutic options for distant metastatic disease, since chemotherapy and external beam radiation therapy for metastatic or cervical recurrent disease have limited response rates. ${ }^{51,52} \mathrm{~A}$ large study of an American cohort of MTC patients demonstrated that age at diagnosis, stage of disease, and extent of surgery are important predictors of survival. Patients with tumor confined to the thyroid gland had a 10-year survival rate of $95.6 \%$, whereas patients with regional stage disease or distant metastasis at diagnosis had overall survival rates of $75.5 \%$ and $40 \%$, respectively. ${ }^{22}$

The main challenge in the management of MTC is patients with advanced and progressive disease, because conventional therapeutic options have poor results for these individuals. Nevertheless, in the last few years, several studies have upgraded our knowledge on the molecular events associated with MTC. RTKs, such as RET and vascular endothelial growth factor-A (VEGFA), involved in proliferation and cell survival, play an important role in the tumorigenesis process. In response to binding of extracellular ligands, such receptors are phosphorylated and activated downstream signaling pathways, such as mitogen-activated protein kinase and phosphatidylinositol 3-kinase pathways, and many signaling effectors, like $\beta$-catenin and nuclear factor-kappa B. ${ }^{53,54}$ Thus, the molecules involved in these processes serve as potential therapeutic targets for new drugs. ${ }^{55}$

\section{Review of therapies targeting receptor tyrosine kinases}

The cumulative knowledge on the distinct signaling pathways and multiple genetic abnormalities involved in the pathogenesis of cancer has allowed the development of targeted molecular therapies. The protein kinases regulate the processes of cell proliferation, differentiation, migration, and antiapoptotic signaling. Protein kinases are characterized by their ability to catalyze the phosphorylation of tyrosine amino acid residues in proteins and thus activate various intracellular signaling pathways. Therefore, tyrosine kinase inhibitors (TKIs) may act as therapy for cancer by blocking the tyrosine kinase-dependent oncogenic pathways. TKIs can be specific to one or several tyrosine kinase receptors, most designed to inhibit multiple signaling pathways. ${ }^{55,56}$

Tyrosine kinase activation plays a key role in the development of MTC; therefore, small-molecule TKIs represent one of the most promising agents for MTC treatment, and 
clinical trials have shown encouraging therapeutic results. The objective Response Evaluation Criteria in Solid Tumors index has been used to evaluate tumor response and is classified as follows: complete response (the disappearance of all target lesions), partial response (at least a 30\% decrease in the sum of the longest diameter of target lesions), progressive disease (at least a $20 \%$ increase in the sum of the longest diameter of target lesions), and stable disease (SD; neither sufficient shrinkage to qualify for partial response nor sufficient increase to qualify for progressive disease). ${ }^{57}$ Interestingly, the reduction in serum levels of tumor markers (calcitonin and CEA) observed with these medications occurs independently of radiological response. ${ }^{58,59}$ Another relevant question concerns the different responses of the parenchymal target lesions (for example, metastasis to lung, liver, bone) vs nonparenchymal target lesions (metastasis in lymph nodes); one possible explanation is that the parenchymal lesions are better perfused. ${ }^{60}$

The most studied TKI drugs for MTC treatment are vandetanib, cabozantinib, motesanib, sorafenib, sunitinib, axitinib, and imatinib (Tables 1 and 2).

\section{Vandetanib (ZD6474, Zactima)}

Vandetanib is an agent that selectively targets RET, vascular endothelial growth factor receptors (VEGFRs), and epidermal growth factor receptors (EGFRs). ${ }^{61,62}$ In human MTC cell lines, vandetanib inhibited the cell proliferation and phosphorylation of RET receptors, EGFR, and mitogenactivated protein kinase pathways. ${ }^{63}$

The activity profile of this drug made it a good choice as a treatment for patients with unresectable MTC. A phase II clinical trial assessed the efficacy of vandetanib (300 mg once daily) in patients with advanced hereditary MTC. A total of 30 patients were enrolled; a partial response was achieved in $20 \%$ of these patients, and durable SD for $\geq 24$ weeks was reported in $53 \%$ of the patients. Therefore, the disease-control rate was $73 \%$, and serum calcitonin levels decreased $50 \%$ or more in $80 \%$ of the patients. ${ }^{64}$ Similar results were described in 19 patients with metastatic hereditary MTC receiving $100 \mathrm{mg} /$ day vandetanib, where the disease-control rate was $68 \% .{ }^{65}$ However, no direct comparison of the efficacy at each dose level - 100 or $300 \mathrm{mg} /$ day - has been conducted.

More recently, in a large trial, 331 adults with metastatic MTC (90\% with sporadic disease) were randomized to receive either vandetanib at a dose of $300 \mathrm{mg}$ daily or placebo. A significant improvement in progression-free survival was observed for patients randomized to receive vandetanib (hazard ratio $0.46,95 \%$ confidence interval $0.31-0.69)$. The rate of mortality at 2-year follow-up was $15 \%$. A subgroup analysis of progression-free survival in sporadic MTC patients suggested that RET M918T mutation-positive patients had a higher response rate to vandetanib compared with RET M918T mutation-negative patients. ${ }^{64,66}$

Table I Summary of clinical trials with tyrosine kinase inhibitors in medullary thyroid carcinoma

\begin{tabular}{|c|c|c|c|c|c|}
\hline Drug & Targets & $\mathbf{N}^{\circ}$ of patients & Partial response (\%) & Stable disease (\%) & Reference \\
\hline \multicolumn{6}{|l|}{ Clinical trials phase I and II } \\
\hline \multirow[t]{2}{*}{ Vandetanib (ZD6474) } & VEGFR-I, VEGFR-2, & 30 & 20 & 53 & 64 \\
\hline & VEGFR-3, RET, EGFR & 19 & 16 & 53 & 65 \\
\hline Cabozantinib (XL 184) & VEGFR-2, RET, MET & 37 & 29 & 41 & 69 \\
\hline \multirow[t]{2}{*}{ Motesanib (AMG 706) } & VEGFR-I, VEGFR-2, VEGFR-3, & 91 & 2 & 48 & 73 \\
\hline & c-Kit, RET, PDGFR & 5 & 40 & 40 & 77 \\
\hline \multirow[t]{2}{*}{ Sorafenib (BAY 43-9006) } & VEGFR-2, VEGFR-3, & 16 & 6 & 50 & 58 \\
\hline & c-Kit, RET & 15 & 25 & - & 78 \\
\hline \multirow[t]{2}{*}{ Sunitinib (SU II I248) } & VEGFR-I, VEGFR-2, & 7 & $28^{\mathrm{a}}$ & $46^{\mathrm{a}}$ & 86 \\
\hline & VEGFR-3, RET, c-Kit & 15 & 33.3 & 26.7 & 87 \\
\hline \multirow[t]{2}{*}{ Axitinib (AG-0I3736) } & VEGFR-I, VEGFR-2, & 11 & 18 & 27 & 89 \\
\hline & VEGFR-3, c-Kit & & & & \\
\hline \multirow[t]{3}{*}{ Imatinib (STI57I) } & RET, c-Kit, PDGFR & 9 & 0 & 55 & 91 \\
\hline & & 15 & 0 & 27 & 92 \\
\hline & & & $\begin{array}{l}\text { PFS drug vs } \\
\text { placebo (months) }\end{array}$ & Hazard ratio & \\
\hline \multicolumn{6}{|l|}{ Clinical trials phase III } \\
\hline Vandetanib (ZD6474) & $\begin{array}{l}\text { VEGFR-I, VEGFR-2, } \\
\text { VEGFR-3, RET, EGFR }\end{array}$ & 331 & 30.5 vs 19.3 & 0.46 & 66 \\
\hline Cabozantinib (XL I84) & VEGFR-2, RET, MET & 330 & II.2 vs 4.0 & 0.28 & 70 \\
\hline
\end{tabular}

Note: ${ }^{a}$ Results for the total number of patients with advanced thyroid cancer, not only MTC patients.

Abbreviations: PFS, progression-free survival; VEGFR, vascular endothelial growth-factor receptor; EGFR, epidermal growth-factor receptor; PDGFR, platelet-derived growth-factor receptor. 
Table 2 Summary of most common reported adverse events of tyrosine kinase inhibitors*

\begin{tabular}{|c|c|c|c|c|c|c|c|}
\hline Adverse events (\%) & $\begin{array}{l}\text { Vandetanib } \\
\text { (ZD6474) }\end{array}$ & $\begin{array}{l}\text { Carbozantinib } \\
\text { (XL I84) }\end{array}$ & $\begin{array}{l}\text { Motesanib } \\
\text { (AMG 706) }\end{array}$ & $\begin{array}{l}\text { Sorafenib } \\
\text { (BAY 43-9006) }\end{array}$ & $\begin{array}{l}\text { Sunitinib } \\
\text { (SU I I 248) }\end{array}$ & $\begin{array}{l}\text { Axitinib } \\
\text { (AG-0I3736) }\end{array}$ & $\begin{array}{l}\text { Imatinib } \\
\text { (STI57I) }\end{array}$ \\
\hline \multicolumn{8}{|l|}{ Gastrointestinal disorders } \\
\hline Diarrhea & $47-77$ & $15.9-57$ & 41 & 71 & 26 & 48 & 43 \\
\hline Dyspepsia & - & - & - & 10 & - & - & 30 \\
\hline Nausea & $16-63$ & 43 & 26 & 14 & 9 & 33 & - \\
\hline Vomiting & $14-40$ & 24 & - & 14 & 9 & 13 & - \\
\hline Oral pain & - & 19 & - & 62 & - & - & - \\
\hline Stomatitis & - & - & - & 48 & - & 25 & - \\
\hline Abdominal pain & 14 & - & - & 29 & - & - & - \\
\hline \multicolumn{8}{|l|}{ Skin events } \\
\hline Acne & 20 & - & - & - & - & - & - \\
\hline Alopecia & - & - & - & 48 & - & - & - \\
\hline Dry skin & 15 & 12 & - & 76 & - & - & - \\
\hline Hand-foot-skin reaction & - & 16.6 & - & 76 & 26 & 15 & - \\
\hline Pruritus & - & - & - & 33 & - & - & - \\
\hline Rash & $45-67$ & 26 & - & 67 & - & 15 & - \\
\hline \multicolumn{8}{|l|}{ Respiratory disorders } \\
\hline Cough & 10 & - & - & - & - & - & \\
\hline Epistaxis & - & - & - & 14 & - & - & - \\
\hline \multicolumn{8}{|l|}{ Cardiovascular disorders } \\
\hline Hypertension & $33-41$ & $7.9-16$ & 27 & 43 & 3 & 28 & - \\
\hline QTc prolongation & 22 & - & - & - & - & - & - \\
\hline \multicolumn{8}{|l|}{ Blood system } \\
\hline Leucopenia & - & - & - & 52 & 31 & - & - \\
\hline Neutropenia & - & - & - & 33 & $34-60$ & - & 8 \\
\hline Thrombocytopenia & - & - & - & 58 & $3-70$ & - & 7 \\
\hline Anemia & - & - & - & 38 & $6-10$ & - & - \\
\hline \multicolumn{8}{|l|}{ Others } \\
\hline Fatigue & $24-63$ & $9.3-55$ & 41 & 5 & 26 & 50 & 70 \\
\hline Anorexia & $16-43$ & - & 27 & 8 & 3 & 30 & 31 \\
\hline Headache & $26-47$ & - & - & 7 & - & 13 & - \\
\hline Proteinuria & - & - & - & - & - & 18 & - \\
\hline
\end{tabular}

Notes: *Irrespective of causality; -, not reported.

Based on these results, the US Food and Drug Administration (FDA) approved vandetanib for the treatment of symptomatic or progressive medullary thyroid cancer in patients with unresectable locally advanced or metastatic disease ${ }^{67}$ Meanwhile, it is important to emphasize that preclinical studies have evidenced that RET-activating mutations at codon 804 (V804L, V804M) cause resistance to some TKIs, such as vandetanib. ${ }^{68}$

\section{Cabozantinib (XLI84)}

XL184 is a potent inhibitor of MET, VEGFR-2, and RET. A phase I study of XL184 (maximum tolerated dose $175 \mathrm{mg}$ daily) was conducted in 37 patients with MTC. Overall, 68\% of patients had SD for 6 months or longer or confirmed partial response. ${ }^{69}$ Data about a phase III study with XL184 in metastatic MTC, presented at the 2012 Annual Meeting of the American Society of Clinical Oncology, demonstrated in an interim analysis that the XL184 treatment resulted in prolongation of progression-free survival when compared with placebo (11.2 vs 4.0 months, respectively).$^{70}$ The XL184 was also recently approved by the FDA for the treatment of MTC, in November 2012.

\section{Motesanib (AMG 706)}

Motesanib is a multikinase inhibitor that targets VEGFR-1, -2, and -3 , platelet-derived growth-factor receptor (PDGFR) and stem cell-factor receptor (c-Kit). In a previous study, this compound potently inhibited angiogenesis in a variety of in vivo models, and it was able to induce regressions of large established tumor xenografts. ${ }^{71}$ Recently, the effects of motesanib on wild-type and mutant RET activity in a mouse model of MTC were described. Treatment with motesanib resulted in substantial inhibition of RET tyrosine phosphorylation and VEGFR-2 phosphorylation in TT tumor cell xenografts. ${ }^{72}$

A single-arm phase II study investigated the efficacy of motesanib (125 mg once daily) in 91 patients with 
advanced MTC. Eighty-one percent of patients had SD, and $48 \%$ had durable SD ( $\geq 24$ weeks); however, the overall response rate observed was only $2 \%$. The clinical benefit rate was 51\% (objective response and durable SD). ${ }^{73}$ Another study found that changes from baseline in serum placental growth factor and soluble VEGFR-2 levels, after initiation of therapy with motesanib, predicted therapeutic responses in patients with metastatic medullary thyroid cancer. ${ }^{74}$

\section{Sorafenib (BAY-43-9006)}

Sorafenib is a multikinase inhibitor with potent activity against Raf and RTKs. Sorafenib inhibits oncogenic RET kinase activity in NIH3T3 cells, while it induces growth arrest in TT cells (C634R RET mutation-positive MTC cell line). Moreover, sorafenib inhibits the growth of cells carrying RET V804L or RET V804M, both mutants that are resistant to other TKIs. ${ }^{75}$ In cell-based assays, sorafenib exhibits potent inhibition of several RTKs involved in tumor angiogenesis and is able to block autophosphorylation of VEGFR-2, VEGFR-3, PDGFR, FMS-like tyrosine kinase 3 (FLT3), and c-Kit. ${ }^{76}$

A small observational study investigated the efficacy of sorafenib in five patients with progressive MTC; after 6 months, two patients showed a partial response, and two patients exhibited SD. ${ }^{77}$ In a phase II trial, 21 patients with metastatic or locally advanced MTC, hereditary or sporadic form, were enrolled to receive $400 \mathrm{mg}$ sorafenib orally twice daily. The hereditary arm of the study was prematurely closed, and it was therefore not possible to conclude on the effect of sorafenib; in the sporadic MTC group, $50 \%$ of the patients demonstrated durable $\mathrm{SD} \geq 15$ months, with only one partial response (6\%). Eleven patients had a decrease in calcitonin and CEA. ${ }^{58}$ More recently, another phase II trial examined a total of 15 patients with metastatic MTC treated with sorafenib. The radiological response rate was achieved for $25 \%$ of patients. ${ }^{78}$

To investigate the hypothesis that combinations of drugs with different therapeutic targets are synergistically effective and thereby could be a better option to treat thyroid malignancies, the combination of sorafenib and tipifarnib - a selective oral farnesyltransferase inhibitor - was employed in a phase I trial. Of the 35 patients studied, 13 had MTC and 22 differentiated thyroid cancer. The MTC partial response rate was $38 \%$ and the SD rate, of at least 6 months, was $31 \%{ }^{79}$ More recently a synergistic effect of sorafenib and AZD6244 (a mitogen-activated protein kinase kinase inhibitor) was demonstrated in the inhibition of human MTC cells, in vitro. ${ }^{80}$ Despite limitations in comparing different studies, it seems that combined treatment offers higher rates of partial response than the use of sorafenib only. Sorafenib is currently approved by the FDA for renal cell and hepatocellular carcinomas.

\section{Sunitinib (SUI I248)}

Sunitinib is a small molecule that inhibits members of the RTK family, including VEGFR-1, VEGFR-2, PDGFR, c-Kit, and RET. ${ }^{81-83}$

Recently, two patients with metastatic MTC received sunitinib $(50 \mathrm{mg} /$ day for 28 days, followed by 14 days of no treatment), with a satisfactory response. ${ }^{84,85}$ In a phase II study, 35 patients with advanced thyroid cancer - seven of them with MTC - received sunitinib at a dose of $37.5 \mathrm{mg}$ daily. The objective response included one complete response $(3 \%)$, ten partial responses $(28 \%)$, and 16 patients $(46 \%)$ with SD. ${ }^{86}$

An ongoing phase II trial aims to determine the efficacy of sunitinib in patients with locally advanced or metastatic thyroid cancer. The partial results of the 15 patients with MTC show 33.3\% partial response and 26.7\% SD for $\geq 12$ weeks. $^{87}$

The FDA has approved sunitinib for treatment of advanced renal cell carcinoma and gastrointestinal stromal sarcomas.

\section{Axitinib (AG-0I3736)}

Axitinib is an oral TKI with selectivity and potency against VEGFR-1, VEGFR-2, and VEGFR-3 ${ }^{88}$ A multicenter, openlabel, phase II study of 60 patients with advanced thyroid cancer, of whom 18\% had MTC, was conducted using $5 \mathrm{mg}$ daily of axitinib. In MTC patients only, the confirmed partial response rate was $18 \%$, and the $\mathrm{SD}$ rate was $27 \%{ }^{89}$

\section{Imatinib (STI57I)}

Imatinib is a TKI used to treat chronic myelogenous leukemia and gastrointestinal stromal tumors. In MTC-derived cell lines expressing mutant RET receptors, imatinib inhibited RET Y1062 phosphorylation and induced cell-cycle arrest and apoptotic cell death. However, the half-maximal inhibitory concentration of imatinib necessary to inhibit RET in vitro is higher than other small-molecule kinase inhibitors of RET activity. ${ }^{90}$ An open-label trial evaluated nine patients with unresectable and progressive MTC treated with imatinib (600 mg daily) for 12 months. A complete or partial response was not seen; after 6 months, five patients had SD, and after 12 months only one. ${ }^{91}$ Similar results were found in another clinical trial with imatinib at the same doses. Of 
the 15 patients with disseminated MTC treated for up to 12 months, four patients had SD over 24 months. ${ }^{92}$

A recent study compared the effect of four TKIs (axitinib, sunitinib, vandetanib, and XL184) on cell proliferation, RET autophosphorylation, and extracellular signal-regulated kinase activation in three cell lines: MZ-CRC-1 (M918T RET mutation), MTC-TT (C634W RET mutation), and TPC-1 (RET/PTC-1 rearrangement) cells. The results showed that all four TKIs were capable of reducing cell proliferation, yet XL184 was the most efficient inhibitor for MEN 2A and vandetanib was the most potent inhibitor for MEN $2 \mathrm{~B} .{ }^{93}$ These data suggest that the use of specific treatments for each mutation could provide additional benefits in the management of metastatic MTC.

\section{Safety and tolerability of receptor tyrosine kinase inhibitor therapies and implications for disease management}

The TKIs are used as chronic therapies, and therefore it becomes important to understand the profile of adverse effects. Generally, these effects are tolerable, and the majority of patients have manageable toxicity. However, TKIrelated serious adverse events leading to death have been also observed and include aspiration pneumonia, respiratory arrest, respiratory failure, sepsis, Staphylococcus infection, and acute heart failure and arrhythmia. ${ }^{66,94,95}$

Common adverse events associated with TKIs are diarrhea, rash, fatigue, and nausea. Other adverse events related to use of TKIs include hypertension, neutropenia, leucopenia, hand-foot syndrome, stomatitis, proteinuria, abdominal pain, facial edema, thrombocytopenia, malaise, laryngeal mucosal swelling, and QTc prolongation, among others (see Table 2)..$^{58,64-66,69,73,77,78,86,87,89,91,92}$ Endocrine dysfunctions are often a side effect of TKI treatment. The most frequent is hypothyroidism, which required an increase in thyroid replacement dose in approximately $50 \%$ of patients. However, the mechanism of hypothyroidism induction is still unclear. ${ }^{96}$

\section{Conclusion and future directions}

Until recently, patients with advanced or metastatic MTC received only palliative care to relieve disabling symptoms, since chemotherapy and radiotherapy have unsatisfactory results. In recent years, cumulative knowledge of molecules and intracellular signaling pathways involved in the pathogenesis of MTC has allowed the use of new targeted therapies.
Different TKIs have been studied in the management of metastatic MTC. The results have demonstrated that TKIs are able to induce partial responses or stabilization of tumor growth. However, it is important to remember that TKIs also interact with physiological functions, causing a number of highly toxic side effects. Moreover, most of the clinical trials were performed on a small number of patients with a brief follow-up period, since tumor growth is very slow in MTC. Therefore, caution is essential in identifying patients who will benefit with such therapies. Gathering information about the targets of action of these drugs as well as TKI-associated side effects will help in choosing the best therapeutic approach to enhance their benefits.

\section{Acknowledgments}

Grant support was received from the Conselho Nacional de Desenvolvimento Científico e Tecnológico (CNPq), Fundação de Amparo a Pesquisa do Rio Grande do Sul (FAPERGS), Fundo de Incentivo a Pesquisa do Hospital de Clínicas de Porto Alegre (FIPE), and the Programa de Apoio a Núcleos de Excelência (PRONEX), Brazil.

\section{Disclosure}

The authors report no conflicts of interest in this work.

\section{References}

1. Hazard JB, Hawk WA, Crile G Jr. Medullary (solid) carcinoma of the thyroid; a clinicopathologic entity. J Clin Endocrinol Metab. 1959;19(1): 152-161.

2. Davies L, Welch HG. Increasing incidence of thyroid cancer in the United States, 1973-2002. JAMA. 2006;295(18):2164-2167.

3. Laure Giraudet A, Al Ghulzan A, Aupérin A, et al. Progression of medullary thyroid carcinoma: assessment with calcitonin and carcinoembryonic antigen doubling times. Eur J Endocrinol. 2008;158(2): 239-246.

4. Meijer JA, le Cessie S, van den Hout WB, et al. Calcitonin and carcinoembryonic antigen doubling times as prognostic factors in medullary thyroid carcinoma: a structured meta-analysis. Clin Endocrinol (Oxf). 2010;72(4):534-542.

5. Girelli ME, Nacamulli D, Pelizzo MR, et al. Medullary thyroid carcinoma: clinical features and long-term follow-up of seventy-eight patients treated between 1969 and 1986. Thyroid. 1998;8(6):517-523.

6. Modigliani E, Cohen R, Campos JM, et al. Prognostic factors for survival and for biochemical cure in medullary thyroid carcinoma: results in 899 patients. The GETC Study Group. Groupe d'étude des tumeurs à calcitonine. Clin Endocrinol (Oxf). 1998;48(3):265-273.

7. Gilliland FD, Hunt WC, Morris DM, Key CR. Prognostic factors for thyroid carcinoma. A population-based study of 15,698 cases from the Surveillance, Epidemiology and End Results (SEER) program 1973-1991. Cancer. 1997;79(3):564-573.

8. Saad MF, Ordonez NG, Rashid RK, et al. Medullary carcinoma of the thyroid. A study of the clinical features and prognostic factors in 161 patients. Medicine (Baltimore). 1984;63(6):319-342.

9. Steiner A, Goodman A, Powers S. Study of a kindred with pheochromocytoma, medullary thyroid carcinoma, hyperparathyroidism and Cushing's disease: multiple endocrine neoplasia, type 2. Medicine (Baltimore). 1968;47(5):371-409. 
10. Pelizzo MR, Boschin IM, Bernante P, et al. Natural history, diagnosis, treatment and outcome of medullary thyroid cancer: 37 years experience on 157 patients. Eur J Surg Oncol. 2007;33(4):493-497.

11. Eng C, Clayton D, Schuffenecker I, et al. The relationship between specific RET proto-oncogene mutations and disease phenotype in multiple endocrine neoplasia type 2. International RET Mutation Consortium analysis. JAMA. 1996;276(19):1575-1579.

12. Mulligan LM, Marsh DJ, Robinson BG, et al. Genotype-phenotype correlation in multiple endocrine neoplasia type 2: report of the International RET Mutation Consortium. J Intern Med. 1995;238(4): 343-346.

13. Decker RA, Peacock ML, Watson P. Hirschsprung disease in MEN 2A: increased spectrum of RET exon 10 genotypes and strong genotypephenotype correlation. Hum Mol Genet. 1998;7(1):129-134.

14. Gagel RF, Levy ML, Donovan DT, Alford BR, Wheeler T, Tschen JA. Multiple endocrine neoplasia type $2 \mathrm{a}$ associated with cutaneous lichen amyloidosis. Ann Intern Med. 1989;111(10):802-806.

15. Machens A, Gimm O, Hinze R, Hoppner W, Boehm BO, Dralle H. Genotype-phenotype correlations in hereditary medullary thyroid carcinoma: oncological features and biochemical properties. J Clin Endocrinol Metab. 2001;86(3):1104-1109.

16. Kebebew E, Ituarte PH, Siperstein AE, Duh Q, Clark OH. Medullary thyroid cancer. Curr Treat Options Oncol. 2000;1(4):359-367.

17. Farndon JR, Leight GS, Dilley WG, et al. Familial medullary thyroid carcinoma without associated endocrinopathies: a distinct clinical entity. Br J Surg. 1986;73(4):278-281.

18. Heshmati HM, Gharib H, van Heerden JA, Sizemore GW. Advances and controversies in the diagnosis and management of medullary thyroid carcinoma. Am J Med. 1997;103(1):60-69.

19. Elisei R, Cosci B, Romei C, et al. Prognostic significance of somatic RET oncogene mutations in sporadic medullary thyroid cancer: a 10-year follow-up study. J Clin Endocrinol Metab. 2008;93(3):682-687.

20. Moura MM, Cavaco BM, Pinto AE, et al. Correlation of RET somatic mutations with clinicopathological features in sporadic medullary thyroid carcinomas. Br J Cancer. 2009;100(11):1777-1783.

21. Mulligan LM, Kwok JB, Healey CS, et al. Germ-line mutations of the RET proto-oncogene in multiple endocrine neoplasia type 2A. Nature. 1993;363(6428):458-460.

22. Roman S, Lin R, Sosa JA. Prognosis of medullary thyroid carcinoma: demographic, clinical, and pathologic predictors of survival in 1252 cases. Cancer. 2006;107(9):2134-2142.

23. Da Silva AM, Maciel RM, Da Silva MR, Toledo SR, De Carvalho MB, Cerutti JM. A novel germ-line point mutation in RET exon 8 (Gly(533) Cys) in a large kindred with familial medullary thyroid carcinoma. J Clin Endocrinol Metab. 2003;88(11):5438-5443.

24. Myers SM, Eng C, Ponder BA, Mulligan LM. Characterization of RET proto-oncogene $3^{\prime}$ splicing variants and polyadenylation sites: a novel C-terminus for RET. Oncogene. 1995;11(10):2039-2045.

25. Takahashi M, Asai N, Iwashita T, Isomura T, Miyazaki K, Matsuyama M. Characterization of the ret proto-oncogene products expressed in mouse L cells. Oncogene. 1993;8(11):2925-2929.

26. Milos IN, Frank-Raue K, Wohllk N, et al. Age-related neoplastic risk profiles and penetrance estimations in multiple endocrine neoplasia type 2 A caused by germ line RET Cys634Trp (TGC > TGG) mutation. Endocr Relat Cancer. 2008;15(4):1035-1041.

27. Frank-Raue K, Höppner W, Frilling A, et al. Mutations of the $R E T$ protooncogene in German multiple endocrine neoplasia families: relation between genotype and phenotype. German Medullary Thyroid Carcinoma Study Group. J Clin Endocrinol Metab. 1996;81(5):1780-1783.

28. Verga U, Fugazzola L, Cambiaghi S, et al. Frequent association between MEN 2A and cutaneous lichen amyloidosis. Clin Endocrinol (Oxf). 2003;59(2):156-161.

29. Donis-Keller H, Dou S, Chi D, et al. Mutations in the RET protooncogene are associated with MEN 2A and FMTC. Hum Mol Genet. $1993 ; 2(7): 851-856$.
30. Frank-Raue K, Rybicki LA, Erlic Z, et al. Risk profiles and penetrance estimations in multiple endocrine neoplasia type $2 \mathrm{~A}$ caused by germline RET mutations located in exon 10. Hum Mutat. 2011;32(1):51-58.

31. Mulligan LM, Eng C, Healey CS, et al. Specific mutations of the RET proto-oncogene are related to disease phenotype in MEN 2A and FMTC. Nat Genet. 1994;6(1):70-74.

32. Punales MK, Graf H, Gross JL, Maia AL. RET codon 634 mutations in multiple endocrine neoplasia type 2 : variable clinical features and clinical outcome. J Clin Endocrinol Metab. 2003;88(6):2644-2649.

33. Gimm O, Marsh DJ, Andrew SD, et al. Germline dinucleotide mutation in codon 883 of the RET proto-oncogene in multiple endocrine neoplasia type 2B without codon 918 mutation. J Clin Endocrinol Metab. 1997;82(11):3902-3904.

34. Smith DP, Houghton C, Ponder BA. Germline mutation of RET codon 883 in two cases of de novo MEN 2B. Oncogene. 1997;15(10): 1213-1217.

35. Menko FH, van der Luijt RB, de Valk IA, et al. Atypical MEN type 2B associated with two germline RET mutations on the same allele not involving codon 918. J Clin Endocrinol Metab. 2002;87(1):393-397.

36. Miyauchi A, Futami H, Hai N, et al. Two germline missense mutations at codons 804 and 806 of the RET proto-oncogene in the same allele in a patient with multiple endocrine neoplasia type $2 \mathrm{~B}$ without codon 918 mutation. Jpn J Cancer Res. 1999;90(1):1-5

37. Zedenius J, Larsson C, Bergholm U, et al. Mutations of codon 918 in the RET proto-oncogene correlate to poor prognosis in sporadic medullary thyroid carcinomas. J Clin Endocrinol Metab. 1995;80(10):3088-3090.

38. Hofstra RM, Fattoruso O, Quadro L, et al. A novel point mutation in the intracellular domain of the RET protooncogene in a family with medullary thyroid carcinoma. J Clin Endocrinol Metab. 1997;82(12): 4176-4178.

39. Bolino A, Schuffenecker I, Luo Y, et al. RET mutations in exons 13 and 14 of FMTC patients. Oncogene. 1995;10(12):2415-2419.

40. Dabir T, Hunter SJ, Russell CF, McCall D, Morrison PJ. The RET mutation E768D confers a late-onset familial medullary thyroid carcinomaonly phenotype with incomplete penetrance: implications for screening and management of carrier status. Fam Cancer. 2006;5(2):201-204.

41. Eng C, Smith DP, Mulligan LM, et al. A novel point mutation in the tyrosine kinase domain of the RET proto-oncogene in sporadic medullary thyroid carcinoma and in a family with FMTC. Oncogene. 1995;10(3):509-513.

42. Eng C, Mulligan LM, Healey CS, et al. Heterogeneous mutation of the RET proto-oncogene in subpopulations of medullary thyroid carcinoma. Cancer Res. 1996;56(9):2167-2170.

43. Siqueira DR, Romitti M, da Rocha AP, et al. The RET polymorphic allele S836S is associated with early metastatic disease in patients with hereditary or sporadic medullary thyroid carcinoma. Endocr Relat Cancer. 2010;17(4):953-963.

44. Romei C, Elisei R, Pinchera A, et al. Somatic mutations of the RET protooncogene in sporadic medullary thyroid carcinoma are not restricted to exon 16 and are associated with tumor recurrence. J Clin Endocrinol Metab. 1996;81(4):1619-1622.

45. Ceolin L, Siqueira DR, Romitti M, Ferreira CV, Maia AL. Molecular basis of medullary thyroid carcinoma: the role of RET polymorphisms. Int J Mol Sci. 2012;13(1):221-239.

46. Elisei R, Cosci B, Romei C, et al. RET exon 11 (G691S) polymorphism is significantly more frequent in sporadic medullary thyroid carcinoma than in the general population. J Clin Endocrinol Metab. 2004;89(7):3579-3584.

47. Gimm O, Neuberg DS, Marsh DJ, et al. Over-representation of a germline RET sequence variant in patients with sporadic medullary thyroid carcinoma and somatic RET codon 918 mutation. Oncogene. 1999;18(6):1369-1373.

48. Robledo M, Gil L, Pollan M, et al. Polymorphisms G691S/S904S of RET as genetic modifiers of MEN 2A. Cancer Res. 2003;63(8): 1814-1817. 
49. Rocha AP, Magalhães PR, Maia AL, Maciel LZ. Genetic polymorphisms: implications in the pathogenesis of medullary thyroid carcinoma. Arq Bras Endocrinol Metab. 2007;5(51):723-730.

50. Scollo C, Baudin E, Travagli JP, et al. Rationale for central and bilateral lymph node dissection in sporadic and hereditary medullary thyroid cancer. J Clin Endocrinol Metab. 2003;88(5):2070-2075.

51. Brierley J, Tsang R, Simpson WJ, Gospodarowicz M, Sutcliffe S, Panzarella T. Medullary thyroid cancer: analyses of survival and prognostic factors and the role of radiation therapy in local control. Thyroid. 1996;6(4):305-310.

52. Nocera M, Baudin E, Pellegriti G, Cailleux AF, Mechelany-Corone $\mathrm{C}$, Schlumberger M. Treatment of advanced medullary thyroid cancer with an alternating combination of doxorubicin-streptozocin and 5 FU-dacarbazine. Groupe d'Etude des Tumeurs à Calcitonine (GETC). Br J Cancer. 2000;83(6):715-718.

53. Ichihara M, Murakumo Y, Takahashi M. RET and neuroendocrine tumors. Cancer Lett. 2004;204(2):197-211.

54. Vieira JM, Santos SC, Espadinha C, et al. Expression of vascular endothelial growth factor (VEGF) and its receptors in thyroid carcinomas of follicular origin: a potential autocrine loop. Eur J Endocrinol. 2005;153(5):701-709.

55. Broekman F, Giovannetti E, Peters GJ. Tyrosine kinase inhibitors: multitargeted or single-targeted? World J Clin Oncol. 2011;2(2):80-93.

56. Schlessinger J. Cell signaling by receptor tyrosine kinases. Cell. 2000;103(2):211-225.

57. Therasse P, Arbuck SG, Eisenhauer EA, et al. New guidelines to evaluate the response to treatment in solid tumors. European Organization for Research and Treatment of Cancer, National Cancer Institute of the United States, National Cancer Institute of Canada. J Natl Cancer Inst. 2000;92(3):205-216.

58. Lam ET, Ringel MD, Kloos RT, et al. Phase II clinical trial of sorafenib in metastatic medullary thyroid cancer. J Clin Oncol. 2010;28(14):2323-2330.

59. Licitra L, Locati LD, Greco A, Granata R, Bossi P. Multikinase inhibitors in thyroid cancer. Eur J Cancer. 2010;46(6):1012-1018.

60. Machens A, Dralle H. Parenchymal versus nonparenchymal target lesion response in clinical trials for metastatic medullary thyroid cancer. J Clin Oncol. 2010;28(28):e534; author reply e535-e536.

61. Carlomagno F, Vitagliano D, Guida T, et al. ZD6474, an orally available inhibitor of KDR tyrosine kinase activity, efficiently blocks oncogenic RET kinases. Cancer Res. 2002;62(24):7284-7290.

62. Wedge SR, Ogilvie DJ, Dukes M, et al. ZD6474 inhibits vascular endothelial growth factor signaling, angiogenesis, and tumor growth following oral administration. Cancer Res. 2002;62(16):4645-4655.

63. Vitagliano D, De Falco V, Tamburrino A, et al. The tyrosine kinase inhibitor ZD6474 blocks proliferation of RET mutant medullary thyroid carcinoma cells. Endocr Relat Cancer. 2011;18(1):1-11.

64. Wells SA Jr, Gosnell JE, Gagel RF, et al. Vandetanib for the treatment of patients with locally advanced or metastatic hereditary medullary thyroid cancer. J Clin Oncol. 2010;28(5):767-772.

65. Robinson BG, Paz-Ares L, Krebs A, Vasselli J, Haddad R. Vandetanib (100 mg) in patients with locally advanced or metastatic hereditary medullary thyroid cancer. J Clin Endocrinol Metab. 2010;95(6) 2664-2671.

66. Wells SA Jr, Robinson BG, Gagel RF, et al. Vandetanib in patients with locally advanced or metastatic medullary thyroid cancer: a randomized, double-blind phase III trial. J Clin Oncol. 2012;30(2):134-141.

67. Deshpande H, Roman S, Thumar J, Sosa JA. Vandetanib (ZD6474) in the treatment of medullary thyroid cancer. Clin Med Insights Oncol. 2011;5:213-221.

68. Carlomagno F, Guida T, Anaganti S, et al. Disease associated mutations at valine 804 in the RET receptor tyrosine kinase confer resistance to selective kinase inhibitors. Oncogene. 2004;23:6056-6063.

69. Kurzrock R, Sherman SI, Ball DW, et al. Activity of XL184 (cabozantinib), an oral tyrosine kinase inhibitor, in patients with medullary thyroid cancer. J Clin Oncol. 2011;29(19):2660-2666.
70. Schoffski P, Elisei R, Müller S, et al. An international, double-blind, randomized, placebo-controlled phase III trial (EXAM) of cabozantinib (XL184) in medullary thyroid carcinoma (MTC) patients (pts) with documented RECIST progression at baseline. J Clin Oncol. 2012; 30 Suppl:5508.

71. Polverino A, Coxon A, Starnes C, et al. AMG 706, an oral, multikinase inhibitor that selectively targets vascular endothelial growth factor, platelet-derived growth factor, and kit receptors, potently inhibits angiogenesis and induces regression in tumor xenografts. Cancer Res. 2006;66(17):8715-8721.

72. Coxon A, Bready J, Kaufman S, et al. Anti-tumor activity of motesanib in a medullary thyroid cancer model. J Endocrinol Invest. 2011;35(2):181-190.

73. Schlumberger MJ, Elisei R, Bastholt L, et al. Phase II study of safety and efficacy of motesanib in patients with progressive or symptomatic, advanced or metastatic medullary thyroid cancer. J Clin Oncol. 2009;27(23):3794-3801.

74. Bass MB, Sherman SI, Schlumberger MJ, et al. Biomarkers as predictors of response to treatment with motesanib in patients with progressive advanced thyroid cancer. J Clin Endocrinol Metab. 2010; 95(11):5018-5027.

75. Carlomagno F, Anaganti S, Guida T, et al. BAY 43-9006 inhibition of oncogenic RET mutants. J Natl Cancer Inst. 2006;98(5):326-334.

76. Wilhelm SM, Carter C, Tang L, et al. BAY 43-9006 exhibits broad spectrum oral antitumor activity and targets the RAF/MEK/ERK pathway and receptor tyrosine kinases involved in tumor progression and angiogenesis. Cancer Res. 2004;64(19):7099-7109.

77. Frank-Raue K, Ganten M, Kreissl MC, Raue F. Rapid response to sorafenib in metastatic medullary thyroid carcinoma. Exp Clin Endocrinol Diabetes. 2011;119(3):151-155.

78. Ahmed M, Barbachano Y, Riddell A, et al. Analysis of the efficacy and toxicity of sorafenib in thyroid cancer: a phase II study in a UK based population. Eur J Endocrinol. 2011;165(2):315-322.

79. Hong DS, Cabanillas ME, Wheler J, et al. Inhibition of the Ras/Raf/ MEK/ERK and RET kinase pathways with the combination of the multikinase inhibitor sorafenib and the farnesyltransferase inhibitor tipifarnib in medullary and differentiated thyroid malignancies. J Clin Endocrinol Metab. 2011;96(4):997-1005.

80. Koh YW, Shah MH, Agarwal K, et al. Sorafenib and Mek inhibition is synergistic in medullary thyroid carcinoma in vitro. Endocr Relat Cancer. 2012;19(1):29-38.

81. Broutin S, Ameur N, Lacroix L, et al. Identification of soluble candidate biomarkers of therapeutic response to sunitinib in medullary thyroid carcinoma in preclinical models. Clin Cancer Res. 2011;17(7):2044-2054.

82. Chow LQ, Eckhardt SG. Sunitinib: from rational design to clinical efficacy. J Clin Oncol. 2007;25(7):884-896.

83. Schueneman AJ, Himmelfarb E, Geng L, et al. SU11248 maintenance therapy prevents tumor regrowth after fractionated irradiation of murine tumor models. Cancer Res. 2003;63(14):4009-4016.

84. Cleary JM, Sadow PM, Randolph GW, et al. Neoadjuvant treatment of unresectable medullary thyroid cancer with sunitinib. J Clin Oncol. 2010;28(23):e390-e392.

85. Kelleher FC, McDermott R. Response to sunitinib in medullary thyroid cancer. Ann Intern Med. 2008;148(7):567.

86. Carr LL, Mankoff DA, Goulart BH, et al. Phase II study of daily sunitinib in FDG-PET-positive, iodine-refractory differentiated thyroid cancer and metastatic medullary carcinoma of the thyroid with functional imaging correlation. Clin Cancer Res. 2010;16(21):5260-5268.

87. Ravaud A, de la Fouchardiere C, Asselineau J, et al. Efficacy of sunitinib in advanced medullary thyroid carcinoma: intermediate results of phase II THYSU. Oncologist. 2010;15(2):212-213; author reply 214.

88. Inai T, Mancuso M, Hashizume H, et al. Inhibition of vascular endothelial growth factor (VEGF) signaling in cancer causes loss of endothelial fenestrations, regression of tumor vessels, and appearance of basement membrane ghosts. Am J Pathol. 2004;165(1):35-52. 
89. Cohen EE, Rosen LS, Vokes EE, et al. Axitinib is an active treatment for all histologic subtypes of advanced thyroid cancer: results from a phase II study. J Clin Oncol. 2008;26(29):4708-4713.

90. de Groot JW, Plaza Menacho I, Schepers H, et al. Cellular effects of imatinib on medullary thyroid cancer cells harboring multiple endocrine neoplasia Type 2A and 2B associated RET mutations. Surgery. 2006;139(6):806-814.

91. Frank-Raue K, Fabel M, Delorme S, Haberkorn U, Raue F. Efficacy of imatinib mesylate in advanced medullary thyroid carcinoma. Eur J Endocrinol. 2007;157(2):215-220.

92. de Groot JW, Zonnenberg BA, van Ufford-Mannesse PQ, et al. A phase II trial of imatinib therapy for metastatic medullary thyroid carcinoma. J Clin Endocrinol Metab. 2007;92(9):3466-3469.
93. Verbeek HH, Alves MM, de Groot JW, et al. The effects of four different tyrosine kinase inhibitors on medullary and papillary thyroid cancer cells. J Clin Endocrinol Metab. 2011;96(6):E991-E995.

94. Lenihan DJ, Cardinale DM. Late cardiac effects of cancer treatment. J Clin Oncol. 2012;30(30):3657-3664.

95. Sheffel R, Dora JM, Siqueira DR, Burttet LM, Cerski MR, Maia AL. Toxic cardiomyopathy leading to fatal acute cardiac failure related to vandetanib: a case report with histopathological analysis. Eur J Endocrinol. 2013;168:K51-K54.

96. Torino F, Corsello SM, Longo R, Barnabei A, Gasparini G. Hypothyroidism related to tyrosine kinase inhibitors: an emerging toxic effect of targeted therapy. Nat Rev Clin Oncol. 2009;6(4):219-228.

\section{Publish your work in this journal}

Cancer Management and Research is an international, peer-reviewed open access journal focusing on cancer research and the optimal use of preventative and integrated treatment interventions to achieve improved outcomes, enhanced survival and quality of life for the cancer patient. The journal welcomes original research, clinical \& epidemiological

\section{Dovepress}

studies, reviews \& evaluations, guidelines, expert opinion \& commentary, case reports \& extended reports. The manuscript management system is completely online and includes a very quick and fair peerreview system, which is all easy to use. Visit http://www.dovepress.com/ testimonials.php to read real quotes from published authors. 